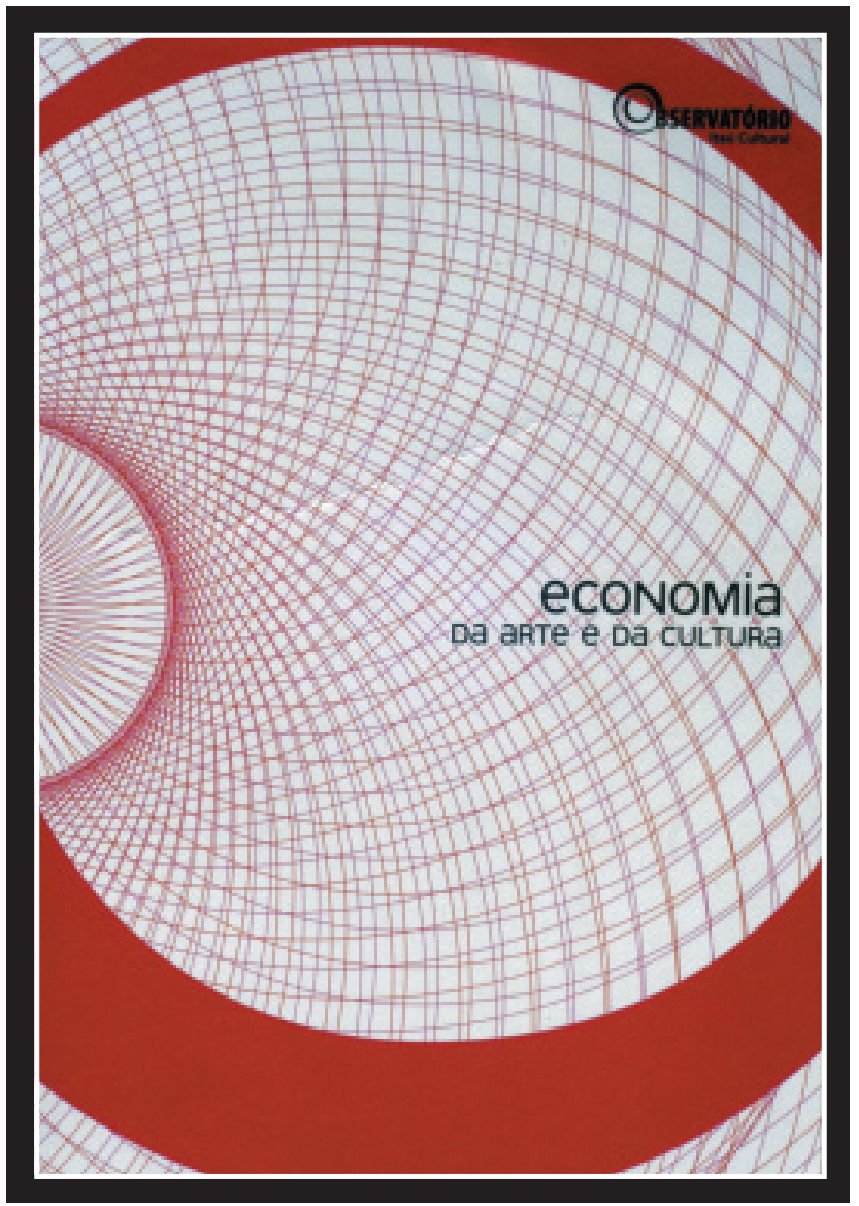

Economia da arte e da cultura, organizado por César Bolaño, Cida Golin e Valério Brittos. São Paulo: Itaú Cultural; São Leopoldo: Cepos/Unisinos; Porto Alegre: PPGCOM/UFRGS; São Cristóvão: Obscom/UFS, 2010, 237 p. 


\title{
Um olhar econômico sobre a fotografia
}

\author{
Bruna Mayara Komarchesqui*
}

A importância da economia na produção cultural e artística é cada vez mais evidente no Brasil. Quantitativamente, ainda faltam instrumentos satisfatórios para medir até que ponto a produção de cultura e arte se relaciona com os poderes políticos e econômicos, funcionando como instrumento de acumulação de capital e reprodução social. Atualmente, o investimento em cultura não só representa ganhos para a imagem das empresas, como é economicamente atrativo, pelos incentivos fiscais que proporciona. Mais recentemente, instituições como o Instituto de Pesquisa Econômica Aplicada (IPEA) e o Instituto Brasileiro de Geografia e Estatística (IBGE) têm se dedicado à tarefa de mensurar até que ponto economia, arte e cultura se cruzam.

O relatório Economia da cultura: análise pelo lado da oferta, produzido pelo IBGE em parceria com o Ministério da Cultura, aponta que, em 2003, o setor cultural abrangia 5,2\% das empresas do país, empregando $4 \%$ do pessoal ocupado e $3,5 \%$ do pessoal ocupado assalariado. Das quase 270 mil empresas, 828 eram dedicadas à pesquisa e desenvolvimento das ciências sociais e humanas, e 33.019 trabalhavam com publicidade e artes fotográficas. Segundo o estudo, o item cultura representava $4,4 \%$ na despesa de consumo não monetária média familiar, na frente de educação, higiene e serviços pessoais. Além dos investimentos privados na área cultural, em 2006, o orçamento do Ministério da Cultura foi de cerca de $\mathrm{R} \$ 450$ milhões.

Um dos grandes desafios relacionados à criação de políticas culturais eficazes e inclusivas é a concentração de bens culturais nas mãos de poucos. Apesar das possibilidades de democratização trazidas pela internet, na

\footnotetext{
* Graduada em Comunicação Social - Habilitação Jornalismo pela Universidade Estadual de Londrina. Estudante especial do Mestrado em Comunicação da mesma instituição. Co-autora do livro O papel do Paraná Norte na construção da Santa Casa e o esporte nas ondas do rádio: duas experiências históricas da imprensa londrinense.
} 
prática, o poder ainda está concentrado nos grandes conglomerados de mídia e em grandes produtores de arte e cultura. Ou seja, quase não há espaço para a diversidade, para as culturas locais e regionais e para produções independentes.

Em tempos de digitalização e convergência de mídias, "[...] tornase urgente estabelecer o diálogo entre os campos da economia convencional, da economia política, da arte e da cultura". (BOLAÑO et al., 2010, p.11). Cumprir essa tarefa é o que pretende o livro Economia da arte e da cultura, que reúne pesquisadores com o objetivo de refletir sobre o sistema artístico e cultural brasileiro, com ênfase na perspectiva histórica. São 11 artigos em que se discute políticas culturais no Brasil, economia política da comunicação, mercado de arte, cinema, artes cênicas, literatura, indústria fonográfica, fotografia e telenovela.

Não há “obra de arte sem o jogo da economia por trás dela", afirma Antonio Hohlfeldt, no prefácio da obra. Arte e economia, de certa forma, sempre foram duas atividades ligadas. Interesses econômicos por trás de produções artísticas remontam à Grécia antiga, onde as elites patrocinavam os grandes festivais teatrais. Mais tarde, durante o Renascimento, os mecenas investiam nas artes como forma de obter reconhecimento e prestígio social. A profusão de aparatos tecnológicos, após a Revolução Industrial, viu esse fenômeno da economia da arte se potencializar. Juntamente com a chamada Indústria Cultural, surgiu o "mercado da arte", que transformou antigos apreciadores em clientes/consumidores.

Se ser mercadoria é uma espécie de sina das obras de arte, não poderia ser diferente com a fotografia, assunto do artigo Vocações da fotografia de imprensa: história, técnicas e efeitos de sentido, de Kati E. Caetano (2010, p.204-216). Desde sua invenção, no século XIX, a fotografia instaurou algumas polêmicas no que diz respeito à sua natureza: Arte ou indústria? Documento fiel ou construção subjetiva do real? Para Caetano (2010, p.204), "o alcance do valor simbólico da fotografia se estende muito além do domínio das ciências e das artes, e seu valor econômico, como mercadoria de outras mercadorias, sobretudo da imprensa e da publicidade, alcançam cifras importantes [...]". 
Nem mesmo os críticos ferrenhos da fotografia como expressão artística resistiram ao poder expressivo do novo invento. Exemplo disso foi Baudelaire, que, apesar de suas críticas, tornou-se um dos escritores mais retratados pelo famoso fotógrafo Nadar. Os interesses econômicos envolvendo a imagem fotográfica levaram também a uma discussão bastante pertinente ao momento atual, dada a proliferação das tecnologias digitais: é lícita a manipulação e o retoque do original? A autora afirma que, ao se virem tragados pela concorrência que praticava o retoque, até os fotógrafos mais resistentes acabaram cedendo à prática.

A economia da fotografia se desenvolveu também com a criação de equipamentos menores e acessíveis à população comum. As câmeras amadoras da Kodak democratizaram definitivamente a fotografia: "Você aperta o botão. Nós fazemos o resto!", dizia a propaganda da época. O barateamento das câmeras e filmes levou a fotografia, antes restrita a revistas e suplementos dominicais, para a imprensa diária. "Nesse domínio, sua vocação realista e testemunhal se fez sentir de maneira mais marcante." (CAETANO, 2010, p.206). Por outro lado, o surgimento da TV foi um grande golpe contra a fotografia como meio documental. Além da migração de verbas publicitárias para o novo veículo, que causou uma crise financeira na imprensa escrita, a televisão impôs algumas mudanças estéticas à fotografia. Segundo Caetano (2010, p.212): “A fotografia, com raras exceções, volta a ter um caráter mais ilustrativo ou chamativo do que informativo."

Arte ou indústria, documento do real ou simples expressão de um ponto de vista, em última instância, a fotografia sempre estará submetida a interesses econômicos. Se por um lado veículos de imprensa e agências de notícias reivindicam para si uma fotografia que mostra o real, por outro, mesmo as expressões mais artísticas da imagem fotográfica não escapam à lógica comercial, quando são expostas em galerias ou publicadas em livros, revistas ilustradas e postais. Com isso, de acordo com Caetano (2010, p.211): "Recupera-se, desse modo, uma distinção iniciada no século XIX, entre a vocação da fotografia para documentar objetivamente e outra para exprimir um ponto de vista." 
O grande mérito de Economia da arte e da cultura está em trazer à tona uma discussão pouco usual nos meios acadêmicos atualmente. Em alguns momentos, a obra peca por ser um tanto partidária do atual governo, sobretudo ao comparar historicamente políticas públicas anteriores com o modelo presente. Não se pode, entretanto, tirar o mérito do trabalho que vem sendo feito pelo Ministério da Cultura, no sentido de democratizar a produção cultural e artística do país, por meio de investimentos em projetos locais e regionais. Pela retrospectiva histórica que faz, pela discussão teórica sobre a economia política da comunicação e da cultura e por seus valiosos dados estatísticos, trata-se de uma leitura válida para estudiosos, produtores culturais e potenciais investidores do mercado de arte brasileiro. 